Check for updates

Cite this: RSC Adv., 2017, 7, 35814

\title{
Highly selective detection of nitrotoluene based on novel lanthanide-containing ionic liquids $\uparrow$
}

\author{
Ling Zheng, ${ }^{a}$ Li-Li Yang, ${ }^{b}$ Nan-Nan Xing, ${ }^{a}$ Yi Pan, ${ }^{a}$ Hong-Xiang Ji, ${ }^{a}$ Jie Wei ${ }^{\star a}$ \\ and Wei Guan (D) *ab
}

Two novel fluorescent ionic liquids based on europium and dysprosium, [MOEMIm] $\left[\mathrm{Ln}\left(\mathrm{NO}_{3}\right)_{4}\right](\mathrm{Ln}=\mathrm{Eu}$, Dy), were synthesized. They exhibited good fluorescence properties under UV-light irradiation, and the phosphor presented bright red $\left(\mathrm{Eu}^{3+}\right)$ and light blue $\left(\mathrm{Dy}^{3+}\right)$ luminescence. This is the first time that the application of lanthanide-based room temperature ionic liquids has been investigated in the field of fluorescence analysis for aromatic compounds. As a fluorescence-quenching sensor for $\mathrm{o}_{-}(\mathrm{m}-, \mathrm{p}-)$ nitrotoluene, trace amounts of the quenchers caused the fluorescence intensity to decrease and produced significant fluorescence quenching. Additionally, $p$-nitrotoluene gave the most significant fluorescence quenching effect among the three isomeric nitrotoluenes; also, the quenching coefficient $K_{\text {sv }}$ was calculated using the Stern-Volmer equation. What's more, the two fluorescent ionic liquids demonstrated high selectivity toward nitrotoluene even in the presence of methylbenzene, phenol, chlorobenzene, and aminobenzene. Hence, the selective recognition of nitrotoluene from other aromatic compounds may be used for the analytical detection of nitrotoluene.

Received 6th June 2017

Accepted 10th July 2017

DOI: $10.1039 / \mathrm{c} 7 \mathrm{ra06300h}$

rsc.li/rsc-advances chromatography coupled with mass spectrometry, ${ }^{18}$ reversedphase high-performance liquid chromatography, ${ }^{19}$ surfaceenhanced Raman spectroscopy, ${ }^{20}$ thermal neutron analysis, ${ }^{21}$ ion mobility spectroscopy ${ }^{22}$ and fluorescence sensing. ${ }^{23-26}$ Among these technologies, the fluorescence quenching method has received considerable attention due to its simplicity, high sensitivity, high selectivity and fast response times. ${ }^{16,27,28}$

As a continuation of our previous work, ${ }^{29}$ we report, for the first time, the successful synthesis of two novel fluorescent ILs containing $\mathrm{Eu}(\mathrm{III})$ and Dy(III) with a 1-(2-methoxyethyl)-3methylimidazolium cation, which exhibit enhanced fluorescence. Interestingly, the fluorescence intensity of the two ILs can be influenced strongly by trace amounts of nitrotoluene, which produces significant fluorescence quenching. This phenomenon is not affected by the presence of possible interferents such as other aromatic compounds. Thus, the reported ionic liquids may have great potential for application in the analytical detection of nitrotoluene.

\section{Materials and methods}

\section{Materials}

$\mathrm{N}$-Methylimidazolium, (2-methoxy)bromoethane, nitrogen, silver nitrate $\left(\mathrm{AgNO}_{3}\right)$, acetonitrile $(\mathrm{ACN})$, dimethyl sulfoxide (DMSO), methanol (MeOH) and ethanol (EtOH) were acquired at analytical reagent grade and used without further purification. They were purchased from Shanghai Chemical Reagent Co. Ltd. Dy $\left(\mathrm{NO}_{3}\right)_{3} \cdot 6 \mathrm{H}_{2} \mathrm{O}$ and $\mathrm{Eu}\left(\mathrm{NO}_{3}\right)_{3} \cdot 6 \mathrm{H}_{2} \mathrm{O}$ were purchased 
from Beijing HWRK Chem Co. Ltd and used without any further purification.

\section{Synthesis of $[\mathrm{MOEMIm}]\left[\operatorname{Ln}\left(\mathrm{NO}_{3}\right)_{4}\right](\mathrm{Ln}=\mathrm{Eu}, \mathrm{Dy})$}

A mixture of $N$-methylimidazolium $(0.18 \mathrm{~mol})$ and ether $(50 \mathrm{~mL})$ was stirred at room temperature under a nitrogen atmosphere; then, (2-methoxy)bromoethane $(0.18 \mathrm{~mol})$ was added via a syringe, and the reaction mixture was stirred for $18 \mathrm{~h}$. The product, 1-(2-methoxyethyl)-3-methylimidazolium bromide [MOEMIm] Br (white solid), was washed with diethyl ether three times and dried in vacuo for 2 days at $353 \mathrm{~K}$. Then 1-(2methoxyethyl)-3-methylimidazolium nitrate ([MOEMIm] $\mathrm{NO}_{3}$ ) was synthesized from [MOEMIm] $\mathrm{Br}$ and $\mathrm{AgNO}_{3}$ in methanol ([MOEMIm] Br: $\mathrm{AgNO}_{3}=1: 1$ ), and the reaction mixture was stirred for $1 \mathrm{~h}$ at room temperature in the absence of light. The product, [MOEMIm] $\mathrm{NO}_{3}$, was prepared through filtration and evaporation in turn. Subsequently, [MOEMIm] $\mathrm{NO}_{3}(9 \mathrm{mmol})$ was added to a mixture of $\mathrm{Dy}\left(\mathrm{NO}_{3}\right)_{3} \cdot 6 \mathrm{H}_{2} \mathrm{O}$ or $\mathrm{Eu}\left(\mathrm{NO}_{3}\right)_{3} \cdot 6 \mathrm{H}_{2} \mathrm{O}(9$ $\mathrm{mmol})$ and acetonitrile $(80 \mathrm{~mL})$ at room temperature, and the mixture was stirred vigorously for $2 \mathrm{~h}$ at $353.15 \mathrm{~K}$. After completion of the reaction, the reaction mixture was cooled to room temperature, and the water and acetonitrile were vaporized under a reduced pressure of $1.0 \pm 0.1 \mathrm{kPa}$ at a temperature of $323-333 \mathrm{~K}$. The products, [MOEMIm] $\left[\mathrm{Ln}\left(\mathrm{NO}_{3}\right)_{4}\right](\mathrm{Ln}=\mathrm{Eu}$, Dy), were dried in vacuo for 2 days at $338 \mathrm{~K}$. The reaction scheme is shown in Fig. 1 and the structures of the products were characterized. For $[\mathrm{MOEMIm}]\left[\mathrm{Eu}\left(\mathrm{NO}_{3}\right)_{4}\right],{ }^{1} \mathrm{H}$ NMR $(600 \mathrm{MHz}$, DMSO, $\delta): 9.15(\mathrm{~s}, 1 \mathrm{H}, \mathrm{N}-\mathrm{CH}=\mathrm{N}), 7.71(\mathrm{~s}, 1 \mathrm{H}, \mathrm{CH}=\mathrm{CH}), 7.75(\mathrm{~s}$, $1 \mathrm{H}, \mathrm{CH}=\mathrm{CH}), 4.36\left(\mathrm{t}, 2 \mathrm{H}, \mathrm{N}-\mathrm{CH}_{2}\right), 3.88\left(\mathrm{~s}, 3 \mathrm{H}, \mathrm{N}-\mathrm{CH}_{3}\right), 3.68$ $\left(\mathrm{t}, 2 \mathrm{H}, \mathrm{O}-\mathrm{CH}_{2}\right), 3.27\left(\mathrm{~s}, 3 \mathrm{H}, \mathrm{O}-\mathrm{CH}_{3}\right)$; elemental analysis (\%) calcd: C, 15.53; H, 2.42; N, 15.53, found: C, 15.31; H, 2.70; N, 15.51; ESI-MS: $m / z\left[\mathrm{M}^{+}\right]$: 141.10, [M $\left.{ }^{-}\right]: 401.23$. For [MOEMIm] $\left[\mathrm{Dy}\left(\mathrm{NO}_{3}\right)_{4}\right],{ }^{1} \mathrm{H} \mathrm{NMR}(600 \mathrm{MHz}, \mathrm{DMSO}, \delta): 9.18(\mathrm{~s}, 1 \mathrm{H}, \mathrm{N}-\mathrm{CH}=$ $\mathrm{N}), 7.80(\mathrm{~s}, 1 \mathrm{H}, \mathrm{CH}=\mathrm{CH}), 7.76(\mathrm{~s}, 1 \mathrm{H}, \mathrm{CH}=\mathrm{CH}), 4.41(\mathrm{t}, 2 \mathrm{H}$, $\left.\mathrm{N}-\mathrm{CH}_{2}\right), 3.92\left(\mathrm{~s}, 3 \mathrm{H}, \mathrm{N}-\mathrm{CH}_{3}\right), 3.74\left(\mathrm{t}, 2 \mathrm{H}, \mathrm{O}-\mathrm{CH}_{2}\right), 3.30(\mathrm{~s}, 3 \mathrm{H}$, $\mathrm{O}-\mathrm{CH}_{3}$ ); elemental analysis (\%) calcd: $\mathrm{C}, 15.24 ; \mathrm{H}, 2.38 ; \mathrm{N}$, 15.23, found: C, 15.16; H, 2.41; N, 15.19; ESI-MS: $m / z\left[\mathrm{M}^{+}\right]$: 141.08, $\left[\mathrm{M}^{-}\right]$: 410.92, no impurity peaks were found (Fig. S1S7 ESI $\dagger$ ).

\section{Fluorescence measurements}

To examine the potential of the samples for sensing aromatic compounds, their absorption was measured using a Cary Eclipse Fluorescence Spectrophotometer (Varian) in a quartz cuvette of $10 \mathrm{~mm}$ optical path length. For the measurements, the suspension containing Eu(III) was excited at $\lambda_{\text {ex }}=394 \mathrm{~nm}$, and the suspension containing Dy(III) was excited at $\lambda_{\mathrm{ex}}=$ $351 \mathrm{~nm}$. The corresponding emission wavelengths were narrow peaks and were monitored from 500 to $650 \mathrm{~nm}$ and 450 to $770 \mathrm{~nm}$, respectively. All of the corresponding fluorescence emission spectra were recorded at room temperature.

\section{Results and discussion}

\section{Optical properties}

The rare earth ILs $[\mathrm{MOEMIm}]\left[\operatorname{Ln}\left(\mathrm{NO}_{3}\right)_{4}\right](\mathrm{Ln}=\mathrm{Eu}$, Dy $)$ displayed excellent fluorescence behaviors under UV light irradiation. We first examined the fluorescence properties of the two ILs dispersed in dimethyl sulfoxide (DMSO) and other common solvents (acetonitrile (ACN), methanol ( $\mathrm{MeOH})$, ethanol (EtOH) and water) at the same concentration (1 M) at room temperature. The fluorescence intensity had nothing to do with the polarity of solvents, and it was the weakest in aqueous solution among the five solvents (Fig. S8 and S9 ESI†). Eventually, due to it combining a strong emission spectrum with the ability to dissolve aromatic compounds, DMSO was selected to be utilized as the final solvent. For Eu(III), Fig. 2a shows typical intense transitions in the emission spectrum at 538, 560, 593, and $617 \mathrm{~nm}$ with excitation at $394 \mathrm{~nm}$ for [MOEMIm] $\left[\mathrm{Eu}\left(\mathrm{NO}_{3}\right)_{4}\right]$ $(0.5 \mathrm{M})$, with the representative derived peaks corresponding to ${ }^{5} \mathrm{D}_{0}-{ }^{7} \mathrm{~F}_{1},{ }^{5} \mathrm{D}_{0}-{ }^{7} \mathrm{~F}_{2},{ }^{5} \mathrm{D}_{0}-{ }^{7} \mathrm{~F}_{3}$, and ${ }^{5} \mathrm{D}_{0}-{ }^{7} \mathrm{~F}_{4}$ transitions. Upon UVlight irradiation, the phosphor presents bright red luminescence. For Dy(III) $(0.1 \mathrm{M})$, the emission spectrum $\left(\lambda_{\mathrm{ex}}=351 \mathrm{~nm}\right)$ showed peaks at 480, 574, 655, and $751 \mathrm{~nm}$ in Fig. 2b, and it presents blue luminescence upon UV-light irradiation, corresponding to the intense transitions of ${ }^{4} \mathrm{~F}_{9 / 2}-{ }^{6} \mathrm{H}_{15 / 2},{ }^{4} \mathrm{~F}_{9 / 2}-{ }^{6} \mathrm{H}_{13 / 2}$, ${ }^{4} \mathrm{~F}_{9 / 2}-{ }^{6} \mathrm{H}_{11 / 2}$, and ${ }^{4} \mathrm{~F}_{9 / 2}-{ }^{6} \mathrm{H}_{9 / 2}$.

\section{Fluorescence properties of nitrotoluene}

Different solutions of nitrotoluene were separately added to the prepared mixtures of ILs [MOEMIm] $\left[\mathrm{Ln}\left(\mathrm{NO}_{3}\right)_{4}\right](\mathrm{Ln}=\mathrm{Eu}$, Dy) and DMSO. The fluorescence measurement results showed that the emission spectrum of $[\mathrm{MOEMIm}]\left[\mathrm{Ln}\left(\mathrm{NO}_{3}\right)_{4}\right](\mathrm{Ln}=\mathrm{Eu}$, Dy) was unchanged in shape with increasing concentration of the quencher, and even a low concentration of nitrotoluene can easily cause fluorescence quenching. This may be caused by the effective interactions with the electron-withdrawing group of nitrotoluene $\left(-\mathrm{NO}_{2}\right)$, which lead to electron transfer between the ILs and the nitrotoluene, consequently leading to significant fluorescence quenching. ${ }^{23}$ The response behavior towards nitrotoluene is shown in Fig. 3 and 4. Both figures show a process of fluorescence quenching and the fluorescence intensity decreases with an increase in the nitrotoluene

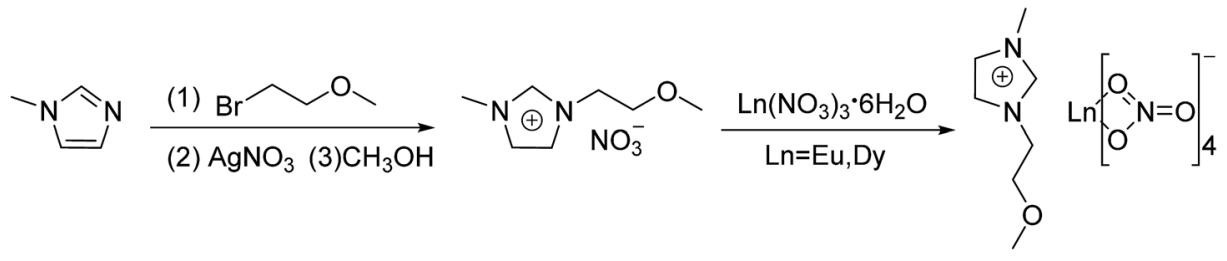

Fig. 1 The reaction scheme of $[\mathrm{MOEMIm}]\left[\mathrm{Ln}\left(\mathrm{NO}_{3}\right)_{4}\right](\mathrm{Ln}=\mathrm{Eu}$, Dy). 

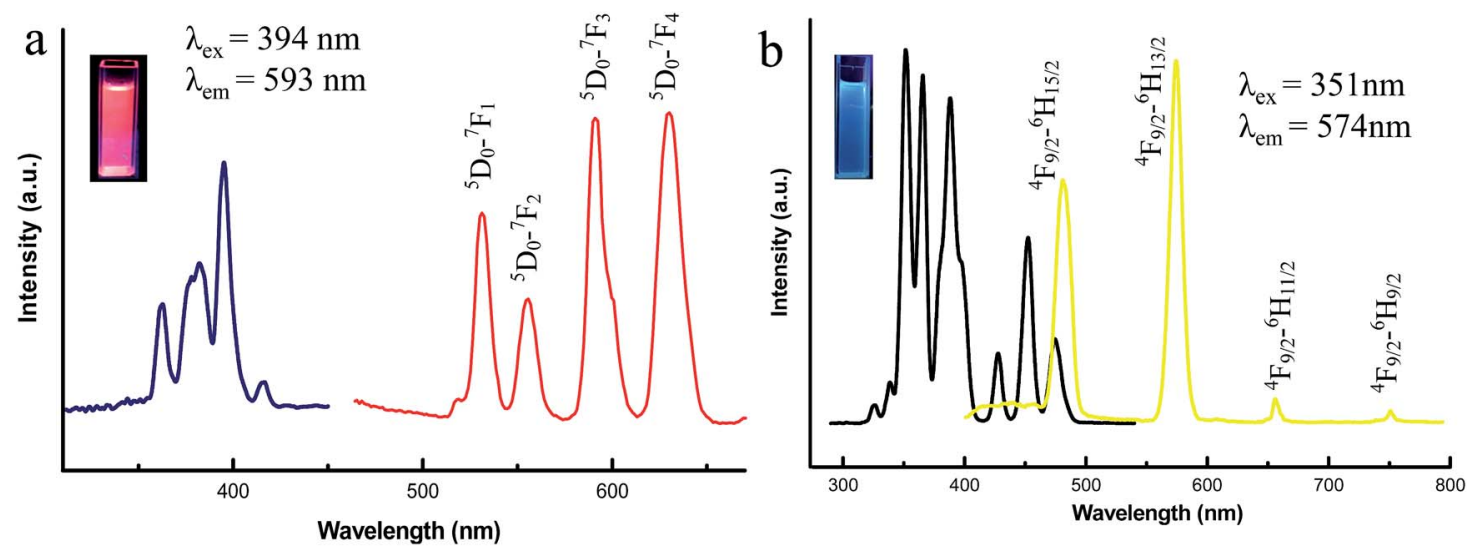

Fig. 2 Excitation and emission spectra of the ILs: (a) [MOEMIm] $\left[\mathrm{Eu}\left(\mathrm{NO}_{3}\right)_{4}\right]$ and (b) $[\mathrm{MOEMIm}]\left[\mathrm{Dy}\left(\mathrm{NO}_{3}\right)_{4}\right]$.

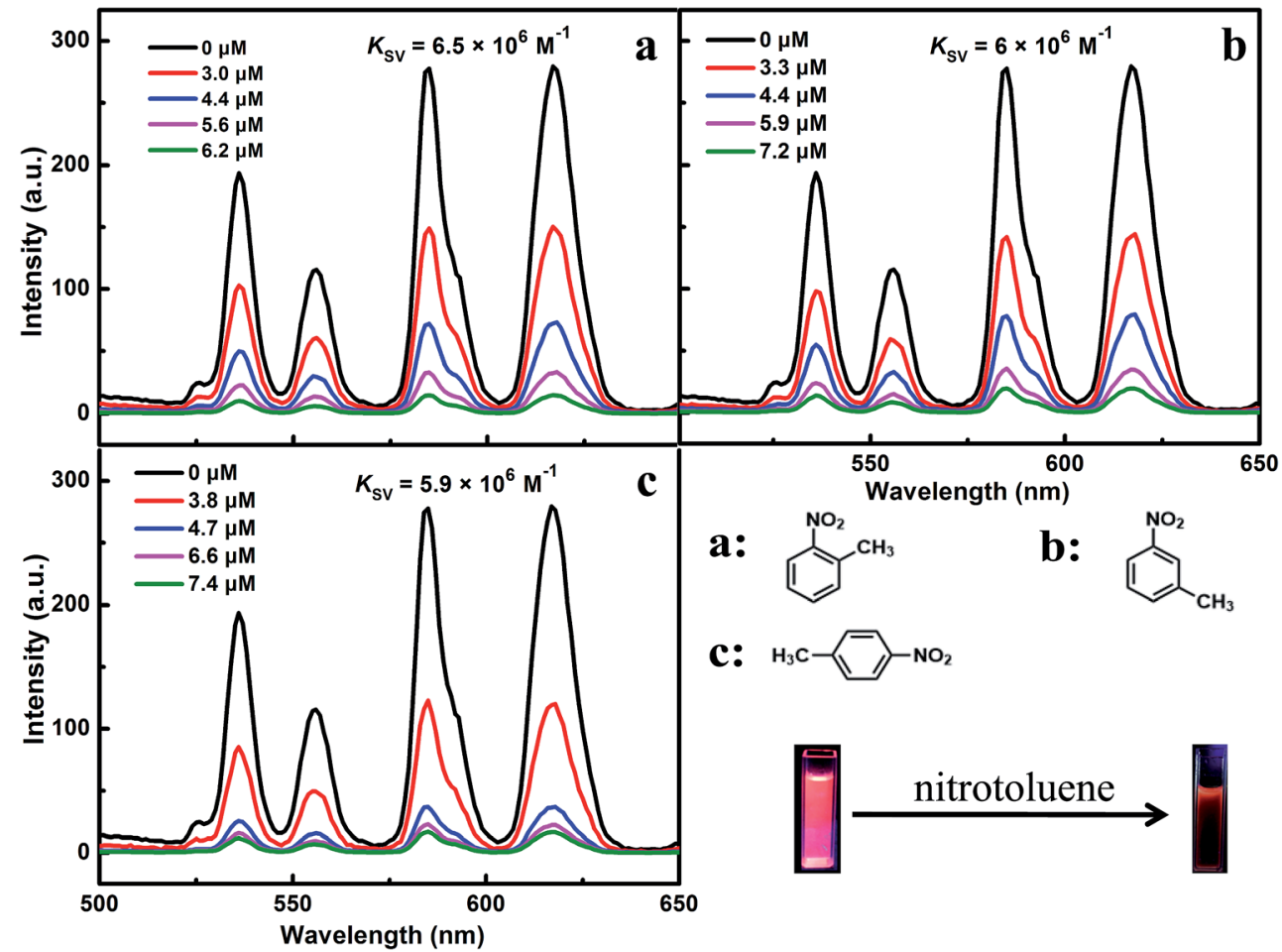

Fig. 3 The photoluminescence response of $[\mathrm{MOEMIm}]\left[\mathrm{Eu}\left(\mathrm{NO}_{3}\right)_{4}\right]$ upon the addition of $\mathrm{o}-(\mathrm{m}-, \mathrm{p}-)_{\text {nitrotoluene. }}$

concentration. Moreover, $p$-nitrotoluene gave a more significant fluorescence quenching effect than $o$ - $(m$-)nitrotoluene, with the order of the quenching performance being as follows: $p$-nitrotoluene $>o$-nitrotoluene $>m$-nitrotoluene. This is the same result as that reported by Wang et $a .^{23}$ When [MOEMIm] $\left[\mathrm{Ln}\left(\mathrm{NO}_{3}\right)_{4}\right](\mathrm{Ln}=\mathrm{Eu}, \mathrm{Dy})$ was exposed to various concentrations of nitrotoluene as a quencher, the dependence of the fluorescence signal in response to nitrotoluene can be described by the Stern-Volmer equation:

$$
I_{0} / I=1+K_{\mathrm{SV}}[\mathrm{Q}]
$$

where $I_{0}$ is the initial fluorescence intensity, $I$ is the fluorescence intensity measured in the presence of the analyte, [Q] is the concentration of the quencher and $K_{\mathrm{SV}}$ is the Stern-Volmer constant. A linear Stern-Volmer behavior was obtained (Fig. S10 and S11 ESI $\dagger$ ) for the lower concentration of nitrotoluene, where the quenching is dominated by a dynamic process. The $K_{\mathrm{SV}}$ values upon the addition of $o-(m-, p$-)nitrotoluene were calculated and are shown in Fig. 3 and 4, respectively. The detection limit (DL) of $p$-nitrotoluene was calculated by using the equation $3 \sigma / K$, where $\sigma$ denotes the standard deviation of the quenching efficiency, and $K$ represents the slope of the equation. The values of DL were $0.14 \mu \mathrm{M}$ for [MOEMIm] $\left[\mathrm{Eu}\left(\mathrm{NO}_{3}\right)_{4}\right]$ and $0.15 \mu \mathrm{M}$ for [MOEMIm] $\left[\mathrm{Dy}\left(\mathrm{NO}_{3}\right)_{4}\right]$ (Fig. S12 and S13 $\mathrm{ESI} \dagger$ ). In addition, for $[\mathrm{MOEMIm}]\left[\mathrm{Eu}\left(\mathrm{NO}_{3}\right)_{4}\right]$, when the concentration of $p$-nitrotoluene was $6.5 \mu \mathrm{M}$, the quenching efficiency was above $92 \%$, which was calculated by using the formula $\left[\left(F_{0}-F\right) /\right.$ 


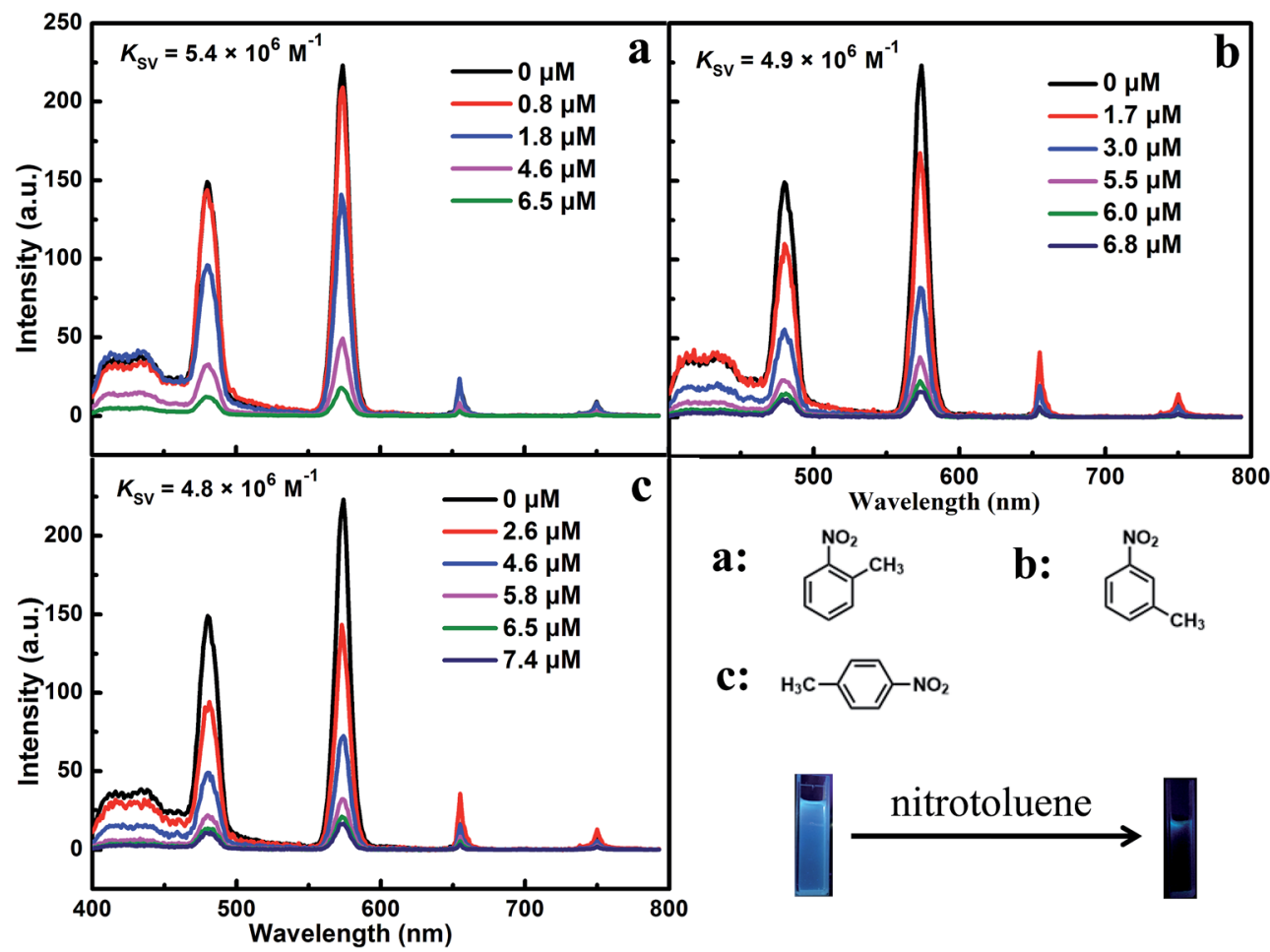

Fig. 4 The photoluminescence response of $[\mathrm{MOEMIm}]\left[\mathrm{Dy}\left(\mathrm{NO}_{3}\right)_{4}\right]$ upon the addition of $o-(m-, p-)$ nitrotoluene.

$\left.F_{0}\right] \times 100 \%\left(F_{0}\right.$ is the initial fluorescence intensity). Similarly, other quenching efficiencies at certain concentrations were also obtained. The changes in fluorescence intensity are shown in Fig. 3 and 4, and the corresponding histograms and color change processes are shown in Fig. S14 and S15. $\dagger$

As can be seen in Fig. 3 and 4, the color of the luminescence images in the process of fluorescence quenching varies from bright red or blue to black under UV light $(\lambda=365 \mathrm{~nm})$, which demonstrates that the fluorescence quenching behavior can also be detected by visual observation.

\section{Fluorescence detection of aromatic compounds}

To investigate the sensing selectivity toward nitrotoluene, the possible interference from some other relevant substances

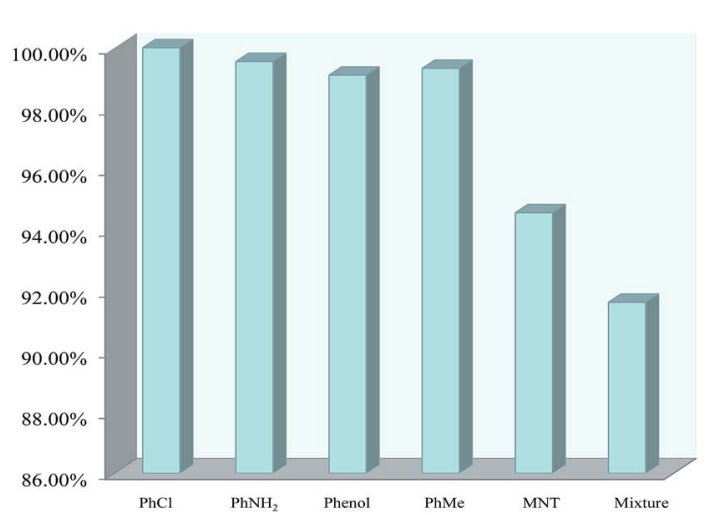

Fig. 5 The fluorescence changes of $\left[\mathrm{MOEMIm]}\left[\mathrm{Eu}\left(\mathrm{NO}_{3}\right)_{4}\right]\right.$ with different aromatic compounds. (methylbenzene, phenol, chlorobenzene and aminobenzene) was investigated. The two samples were first dissolved in DMSO (1 M) containing methylbenzene, phenol, aminobenzene, chlorobenzene and $p$-nitrotoluene, respectively. As can be seen in Fig. 5 and 6 , the fluorescence intensity remained almost unchanged with the addition of methylbenzene, phenol, chlorobenzene and aminobenzene, but significantly decreased in the presence of nitrotoluene. This indicates that the fluorescence intensity is not influenced by the former four compounds, but is obviously quenched by $p$-nitrotoluene. To further investigate the high selectivity for $p$-nitrotoluene over other aromatic compounds, a mixture containing methylbenzene, phenol, aminobenzene, chlorobenzene and $p$-nitrotoluene was

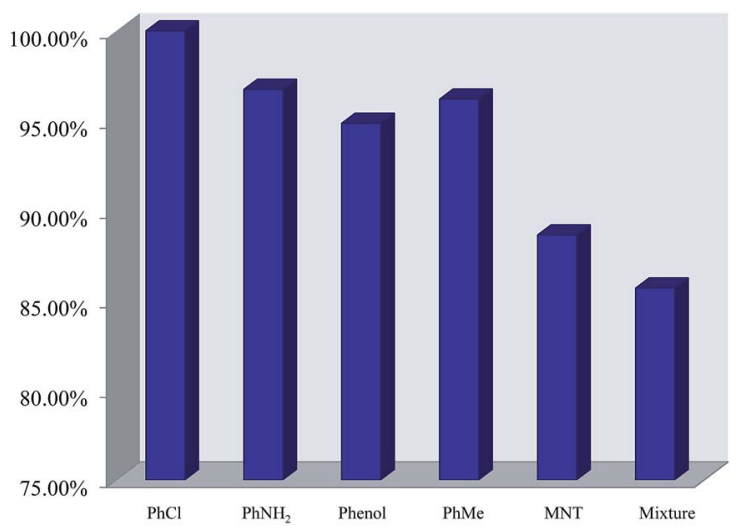

Fig. 6 The fluorescence changes of $[\mathrm{MOEMIm}]\left[\mathrm{Dy}\left(\mathrm{NO}_{3}\right)_{4}\right]$ with different aromatic compounds. 
prepared and added to the Dy(III) or Eu(III)-based ionic liquid in DMSO. Under the irradiation of UV light at $365 \mathrm{~nm}$, the test sample showed a difference in color compared with the original one that was visible to the naked eye. The measurement of the emission spectrum indicated that the selectivity for nitrotoluene was not affected by the existence of other common aromatic compounds.

\section{Conclusions}

Two novel fluorescent ionic liquids based on europium and dysprosium, [MOEMIm] $\left[\mathrm{Ln}\left(\mathrm{NO}_{3}\right)_{4}\right](\mathrm{Ln}=\mathrm{Eu}$, Dy), were synthesized, and exhibit good fluorescence properties under UV-light irradiation, with the phosphor presenting bright red $\left(\mathrm{Eu}^{3+}\right)$ and light blue $\left(\mathrm{Dy}^{3+}\right)$ luminescence. Furthermore, we investigated the application of the lanthanide-based room temperature ionic liquids in the field of fluorescence analysis. When trace amounts of $o-(m-, p$-)nitrotoluene were added, the fluorescence intensity decreased and significant fluorescence quenching was observed. Among the three isomeric nitrotoluenes, $p$-nitrotoluene gave the most significant fluorescence quenching effect compared to that of $o$ - $(\mathrm{m}$-)nitrotoluene. Moreover, the two fluorescent ionic liquids demonstrated high selectivity toward nitrotoluene, even in the presence of aromatic compounds. Therefore, the selective recognition of nitrotoluene over other aromatic compounds may be used for explosives detection.

\section{Acknowledgements}

The project was supported by the National Natural Science Foundation of China (21673107) and LNET (LR2015025).

\section{Notes and references}

1 Z. Y. Yan and B. Yan, New J. Chem., 2014, 38, 2604-2610.

2 M. Pal, K. Behera and S. Pandey, Colloids Surf., A, 2016, 507, 227-235.

3 G. S. Medina and M. Reta, J. Sep. Sci., 2016, 39, 4209-4218.

4 K. Damarla, P. Bharmoria, K. S. Rao, P. S. Gehlot and A. Kumar, Chem. Commun., 2016, 52, 6320-6323.

5 M. Baloch, A. Vizintin, R. K. Chellappan, J. Moskon, D. Shanmukaraj, R. Dedryvee're, T. Rojo and R. Dominko, J. Electrochem. Soc., 2016, 163, 2390-2398.

6 C. C. Hall, C. Zhou, S. P. O. Danielsen and T. P. Lodge, Macromolecules, 2016, 49, 2298-2306.
7 G. Saielli and Y. Wang, J. Phys. Chem. B, 2016, 120, 91529160.

8 C. Banerjee, A. Roy, N. Kundu, D. Banik and N. Sarkar, Phys. Chem. Chem. Phys., 2016, 18, 14520-14530.

9 S. Wang, X. L. Yin, Y. Yan, Z. Y. Xiang, P. Liu, Y. Chen, X. Xin and Y. Z. Yang, Ind. Eng. Chem. Res., 2016, 55, 8207-8214.

10 X. D. Wen, Y. Gao, P. Wu, Z. Q. Tan, C. B. Zheng and X. D. Hou, J. Anal. At. Spectrom., 2016, 31, 415-422.

11 X. Tian, X. J. Qi, X. Y. Liu and Q. H. Zhang, Sens. Actuators, B, 2016, 229, 520-527.

12 H. T. Temiz, U. Tamer, A. Berkkan and I. H. Boyaci, Talanta, 2017, 167, 557-562.

13 J. Shen, C. Sun and X. Wu, Talanta, 2017, 165, 369-376.

14 X. Deng and D. Wu, RSC Adv., 2014, 4, 42066-42070.

15 M. He, Y. Sun, X. Li and Z. Yang, Chemosphere, 2006, 65, 365374.

16 K. Volkan Özdokur, L. Pelit, H. Ertaş, S. Timur and F. N. Ertaş, Talanta, 2012, 98, 34-39.

17 B. S. Crimmins and J. E. Baker, Atmos. Environ., 2006, 40, 6764-6779.

18 K. Schoene, H. J. Bruckert, J. Steinhanses and A. Koenig, Fresenius. J. Anal. Chem., 1994, 348, 364-370.

19 K. Kalikova, R. Geryk, J. Vozka and E. Tesarova, J. Sep. Sci., 2015, 38, 711-719.

20 M. M. Liu and W. Chen, Biosens. Bioelectron., 2013, 46, 6873.

21 G. Vourvopoulos and P. C. Womble, Talanta, 2001, 54, 459468.

22 J. M. Perr, K. G. Furton and J. R. Almirall, J. Sep. Sci., 2005, 28, 177-183.

23 F. Q. Wang, Z. C. Yu, C. M. Wang, K. H. Xu, J. G. Yu, J. X. Zhang, Y. Y. Fu, X. Y. Li and Y. N. Zhao, Sens. Actuators, B, 2017, 239, 688-695.

24 B. Xing, H. Y. Li, Y. Zhu, Z. Zhao, Z. G. Sun, D. Yang and J. Li, RSC Adv., 2016, 6, 110255-110265.

25 D. Wang, L. Sun, C. Hao, Y. Yan and Z. Liang, RSC Adv., 2016, 6, 57828-57834.

26 S. N. Zhao, X. Z. Song, M. Zhu, X. Meng, L. L. Wu, S. Y. Song, C. Wang and H. Zhang, RSC Adv., 2015, 5, 93-98.

27 T. M. Geng, S. N. Ye, W. Yu, H. Zhu, X. Wang and X. Liu, Talanta, 2017, 165, 282-288.

28 N. Ferretto, M. Tedetti, C. Guigue, S. Mounier, R. Redon and M. Goutx, Chemosphere, 2014, 107, 344-353.

29 B. H. Fan, J. Wei, X. X. Ma, X. X. Bu, N. N. Xing, Y. Pan, L. Zheng and W. Guan, Ind. Eng. Chem. Res., 2016, 55, 2267-2271. 